\title{
Concentration-dependent electrochemical synthesis of quantum dot and nanoparticles of copper and shape-dependent degradation of methyl orange
}

\author{
Kalawati Saini ${ }^{*}$, Rajaya Shree Pandey ${ }^{2}$ \\ ${ }^{1}$ Miranda House, Department of Chemistry, University of Delhi, New Delhi 110007, India \\ ${ }^{2}$ Department of Chemistry, University of Rajasthan, Jaipur, Jaipur 302004, India
}

*Corresponding author: Tel: (+91) 9899933847; Fax: (+91) 1127667437; E-mail: kalawati.saini@ mirandahouse.ac.in

Received: 05 February 2017, Revised: 14 February 2017 and Accepted: 09 April 2017

DOI: $10.5185 /$ amlett.2017.1663

www.vbripress.com/aml

\begin{abstract}
Quantum dot of copper $(\mathrm{Cu})$ and nanoparticles of copper and copper oxide $\left(\mathrm{Cu}_{2} \mathrm{O}, 6 \mathrm{CuOCu}_{2} \mathrm{O}, \mathrm{Cu}_{3} \mathrm{O}_{4}\right)$ were synthesized by electrochemical route using the tri-sodium citrate (TSC) and ascorbic acid as a capping and reducing agent. The synthesis was done at $3.2 \mathrm{~V}, 311 \mathrm{~K}$ and $15 \mathrm{~V}, 373 \mathrm{~K}$ using copper rod as a working electrode and platinum wire as a reference electrode. The electrochemical set up was kept under inert nitrogen-purged conditions. $\mathrm{Cu}$ nanoparticles were synthesized in large-scale for the first time by direct dissolution of $\mathrm{Cu}^{2+}$ into the solution of capping agent from copper electrode in the electrochemical cell. Nanoparticles were characterized by using UV-visible absorption spectroscopy, scanning electron microscopy (SEM), transmission electron microscopy (TEM), and X-ray diffraction (XRD) techniques. High resolution TEM pictures showed the formation of different shapes of nanostructures such as spherical, dendrites and leaf-shape respectively. The copper nanoparticles in presence of $200 \mathrm{mM}$ of ascorbic acid were obtained with sizes of $2.10-4.81 \mathrm{~nm}$ in spherical shape and 24.5 $49.4 \mathrm{~nm}$ with $2.88 \mathrm{mM}$ of ascorbic acid. At lower concentration, the particles were also obtained in leaf-shape with ascorbic acid. The leaf shape was also obtained with $250 \mathrm{mM}$ of TSC. This new kind of synthesis method shows the excellent stability compared with that of another chemical method of copper nanoparticles. These particles were used for degradation of methyl orange. The kinetic study of methyl orange with leaf shape particle capping via TSC shows complete degradation of methyl orange in $120 \mathrm{~min}$. Copyright $\odot 2017$ VBRI Press.
\end{abstract}

Keywords: Copper nanoparticles, tri-sodium citrate (TSC), direct dissolution, working electrode, platinum wire.

\section{Introduction}

Metal nanoparticles have attracted much attention of researchers and scientist towards the nanoscale science and engineering technology over the past decades due to their physical and unusual chemical properties. It is due to their large surface to volume ratio and quantum size effect. Copper nanoparticles are of great interest due to their easy synthesis and potential applications in different fields. Plasmonic nanostructures (NS) are resourceful class of nanomaterials finding significant applications in different areas such as nano-medicine [1-4], bio-imaging [5], photothermal therapy [6-8] to plasmonic solar cells [9-11] and nano-antennas [12]. The origin of these applications of plasmonic NS lies in the phenomenon called Localized Surface Plasmon Resonance (LSPR) associated with this intriguing class of NS. Copper based NS such as metallic copper, its oxides have been recently noticed to show the LSPR that makes them widely applicable as a catalyst say in electro-catalysis [13-14], photo-catalysis [15-17], optoelectronics [18] and energy storage [19-20] etc. Methyl orange dye (MO) which has been commonly used in the laboratory, colouring agents in leather, food, textile, pharmaceutical industries. Methyl orange is not easily degradable and is carcinogenic and mutagenic.

Photo catalytic degradation of methyl orange has been studied using $\mathrm{ZnO}$ nanopowders [21]. Photo catalytic splitting of seawater and degradation of methylene blue have been done on $\mathrm{CuO} /$ nanoTiO$_{2}$ [22].

The interests in copper oxide are continuously growing due to its exotic electronic properties and thermal conductivities associated with their nano-dimension that are dependent on stoichiometry of copper and oxygen in a synthesized NS [23-25]. Additionally, it is base material i.e. copper is inexpensive, abundant and non-toxic. It can be prepared in bulk quantities. Beside nano-dimension of copper/copper oxide NS, the shape brings into another degree of freedom to vary and control their properties which exert tremendous impact on their applications. For example, the atomic arrangement in different facets that are exposed due to variation in shape will have profound effect on their catalytic properties. Therefore, activation of copper oxide by changing its particle shape to expose its most active catalyst site would yield efficient and economic catalyst material which in turn can be achieved by developing facile, cheap 
and sustainable approach for preparing copper oxide NS with various shapes.

Nowadays, several methods are being applied to prepare copper and cuprous oxide NS, such as evaporation deposition, chemical reduction, microwave irradiation, micro-emulsion, mechano-chemical synthesis, and electrochemical processes [26-30]. Among these methods, the electrochemical method which involves lesser cost and has no environmental pollution, is considered to be more attractive [30]. The copper nanoparticles have been prepared in aqueous media by electro-deposition at higher overpotentials corresponding to the limiting diffusion current density. Particularly, electrolysis has been fairly used to prepare copper oxide in powder form due to its simple process and handling that is also easy to control.

Nano and ultra-fine copper particles have been synthesized by novel electro-deposition method and the effect of electrolysis parameters on the morphology of copper particles has been studied. The effect of different additives on the electro-deposition of copper powder and its surface engineering has also been studied [31- 32]. The effect of the anode material on the composition and dimensional characteristics of the nano-sized copper powder have been reported by $\mathrm{V}$. Tesakova [32]. The effect of new additives like lanolin on the electro-deposition of copper powder has also been studied by S. Jafer [33] and coworkers. Influence of the interaction between chloride and thiourea on copper electro-deposition has been reported by S. Tantavichet [34]. Unfortunately, different synthetic routes under totally different experimental conditions are responsible for generating various shapes of copper/copper oxide NS. Thus, the development of a unified approach towards facile and sustainable synthetic protocol for the controlled synthesis of copper/copper oxide with different shapes is still a challenging task. Therefore, preparing plasmonic copper/copper oxide NS with varying shapes in an economic and unified way is highly demanding.

Here, we report our successful attempt towards facile and sustainable synthesis of multidimensional plasmonic copper/copper oxide $\left(\mathrm{Cu}_{2} \mathrm{O}, 6 \mathrm{CuCu}_{2} \mathrm{O}, \mathrm{Cu}_{3} \mathrm{O}_{4}\right)$ NS with ascorbic acid as a capping agent at two different concentration using simple electrolysis technique. The synthesis has been done at of $3.2 \mathrm{~V}, 311 \mathrm{~K}$ and $15 \mathrm{~V}, 373 \mathrm{~K}$ using copper rod as a working electrode and Platinum wire as a reference electrode. We found that, ascorbic acid play an important role of shape directive agent. Furthermore, the ascorbic acid has found to help in anodic electro-dissolution of $\mathrm{Cu}$ rod into $\mathrm{Cu}^{2+}$ ions at much lower applied potential as compared to that of without ascorbic acid. The prepared materials have been thoroughly characterized for their morphological, structural and photocatalytic properties. We have also prepared nanostructure of copper with tri-sodium citrate (TSC) with six different shapes using same method. The degradation of methyl orange has been reported herein for comparable photocatalytic study. To best of our knowledge, developed protocol for the synthesis of plasmonic copper/copper oxide NS is unique and is not reported before in the literature. Nano size particles obtained from this method play very important role in the degradation of methyl orange (MO) dyes in presence of $0.1 \mathrm{M} \mathrm{NaOH}$ at room temperature which is one of the most dangerous organic pollutants.

\section{Experimental}

\section{Materials / chemicals details}

All chemicals used for the synthesis were of analytical reagent grade. Tri-sodium citrate and ascorbic acid (99\%) purchased from Merck Limited, India. Ultrapure $\mathrm{Ar}$ and $\mathrm{N}_{2}$ gases were purchased from Sigma Gases, New Delhi and before using were passed through a filter equipped with an oxygen trap, gas purifier and moisture trap to remove the traces of impurities. Copper metal rod $(99.9 \%$ pure, metal basis) was obtained from Alfa Aesar. All other chemicals were used as such without any further purification.

\section{Material synthesis}

Tri-sodium citrate and ascorbic acid capped copper/copper oxide NS were synthesized via electrochemical route that can be divided into two sets. Set-1 was carried out at $311 \mathrm{~K}$ temperature and applied potential of $3.2 \mathrm{~V}$. The concentration of TSC was taken $50 \mathrm{mM}, 200 \mathrm{mM}$ and 250 $\mathrm{mM}$ respectively whereas ascorbic acid was taken $200 \mathrm{mM}$ in case of Set-1. The Set- 2 was carried out at $373 \mathrm{~K}$ and applied potential of $15 \mathrm{~V}$ with $2.88 \mathrm{mM}$ ascorbic, $2.55 \mathrm{mM}$ and $200 \mathrm{mM}$ TSC respectively. Electrochemical synthesis set up was formed by immersing the copper electrode (anode) and platinum wire (cathode) in solutions of ascorbic that was kept $100 \mathrm{~mL}$ in each set. Both the electrodes were connected with a DC power supply and desired potential (either $3.2 \mathrm{~V}$ or $15 \mathrm{~V}$ ) was applied for a fixed time interval of two hours. The electrolysis of copper was carried out either in air or under inert nitrogen-purged conditions using an electrochemical cell equipped with a magnetic stirrer at $350 \mathrm{rpm}$. The solution turns brownish in color after ca. 30 minutes indicating the formation of copper/copper oxide NS in the electrolyte solution. The particles start accumulating or adsorbing at the Pt cathode when the potential is being applied and as soon as the power supply is switched off, the copper/copper oxide NS gets stripped off from the cathode in the form of precipitate and settle down the bottom of an electrochemical cell. Thus, obtained precipitate is then filtered with Whatmann filter paper number 42 and was washed several times with de-ionized water and then dried under vacuum oven. The reddish-brown powder was then collected and used for further characterization. The schematic electrochemical synthesis set-up and mechanistic approach have been shown in Fig. S1. When copper electrode is taken as anode it oxidizes to give cupric ions in solution. These ions may undergo further hydrolysis to form soluble molecular precursors (see in supportive information, Fig. S1). On increasing the reaction time, the color of the solution changes from colorless to blue indicating complexation of the water with copper. The solution turns in copper color/brownish in color after ca. 30 minutes indicating the formation of copper/copper oxide NPs in the electrolyte solution. 


\section{Characterizations}

The UV-visible absorption measurements were recorded with Perkin-Elmer Lambda Bio 20 UV-vis spectrophotometer at a resolution of $1 \mathrm{~nm}$. Powder X-ray diffraction (PXRD) measurements of the dried powder have been done by filling it in to the groove of quartz glass sample holder of a Bruker D8 Advance diffractometer with $\mathrm{Ni}$-filtered $\mathrm{CuK}_{\alpha}$ radiation. The data was collected in the $2 \theta$ range of $10-80^{\circ}$ with a step size of $0.02^{\circ}$ and a step time of $1 s$. The field emission scanning electron microscope (FE SEM) attached with Oxford-EDS system IE 250X max 80 with latest $80 \mathrm{~mm} 2$ model FEI Quanta 200 were used to determine morphology and elemental composition of the prepared materials. The surface morphology was studied by recording the transmission electron microscopy (TEM) images of these samples by using Tecnai $\mathrm{G}^{2}$ F 20 TWIN TMP Series of the microscope, Model FEG 200KV. SEM with EDX analyses were also done using an energydispersive X-ray spectroscope (JEOL JSM 6610). SEM with EDS analyses were also done by Bruker Nano GmbH, Germany, Quantax.

\section{Results and discussion}

\section{Set-1: Applied potential of $3.2 \mathrm{~V}$ at $311 \mathrm{~K}$}

In this synthesis, $\mathrm{Cu}$ and $\mathrm{Cu}_{2} \mathrm{O}$ NS are formed following the nucleation of the growth species by electrochemical reaction followed by subsequent growth process. When the potential is applied, copper first get oxidize into +2 oxidation states generating $\mathrm{Cu}^{2+}$ species which in presence of ascorbic acid capping ligands reduces back into $\mathrm{Cu}^{\circ}$ oxidation state (i.e. nucleation). Depending upon the applied potential, the number of nuclei formed may vary and thus leads to the different shapes of NS. The $\mathrm{Cu}^{\circ}$ nuclei then undergo growth process to generate NS where the growth process is controlled by diffusion of growth species which in turn depends upon the citrate additive concentration. Overall, the nucleation and growth kinetics is controlled by varying only two of the parameters viz. concentration of ascorbic acid additives and the applied potential/voltage between $\mathrm{Cu}$ rod anode and Pt wire cathode. The copper hydroxide then based on the reaction conditions, may undergo transformation into either $\mathrm{CuO}$ or $\mathrm{Cu}_{2} \mathrm{O}$. Metallic copper formed may also undergo oxidation with oxygen (either from dissolved in solution or from air) and leads into formation of $\mathrm{Cu}_{2} \mathrm{O}$ layer on the surface of metallic $\mathrm{Cu}$ NS. In the present synthesis protocol, $\mathrm{Cu}_{2} \mathrm{O}$ seem to predominate as the major product is a mixed phase of $\mathrm{Cu}_{2} \mathrm{O}$ and $\mathrm{Cu}$ NS. Fig. 1 (a) shows UV-vis absorption spectra recorded on the as prepared sol in aqueous solution at room temperature with $50 \mathrm{mM}$ (black curve), $200 \mathrm{mM}$ (red curve) and $250 \mathrm{mM}$ (blue curve) of TSC additive at an applied potential of $3.2 \mathrm{~V}$. The first two closely spaced absorption bands positioned at ca. $250 \mathrm{~nm}$ and $280 \mathrm{~nm}$ are common to all the samples and correspond to the oxidation product of citrate moieties used in the synthesis set up. Similar observations were noticed by us while studying the role of citrate moieties anchored to the Q$\mathrm{CdSe}$ surface in seed mediated synthesis of Ag nanoparticles [35-36]. The oxidation of citrate moieties can be expected considering its well-known role as a reducing agent for reduction of metal ions to prepare metal nanoparticles in several synthetic strategies [37-40]. In the present case, these peaks can be attributed to the oxidation product of citrate moieties used for assisting the electro-dissolution and stabilization process. This can also be supported by the continuous increase in the absorbance of these absorption bands with increasing concentration of tri-sodium citrate from $50 \mathrm{mM}$ to $250 \mathrm{mM}$ (used in the synthesis protocol). Similar observations have been reported by Xiong et al [41] for oxidation products of ascorbic acid during the synthesis of $\mathrm{Cu}$ NS. They have further confirmed it by studying the absorption spectra of ascorbic acid oxidation in presence of $\mathrm{H}_{2} \mathrm{O}_{2}$.

The next set of peaks centered close to $738 \mathrm{~nm}$ in the absorption spectra of these samples (Fig. 1(a)) with slightly varying peak positions are obtained and can be attributed to the signature optical response of interest which is known as the localized surface plasmon resonance (LSPR) from metallic $\mathrm{Cu}$ surrounded with the $\mathrm{Cu}_{2} \mathrm{O}$ shell [42]. The LSPR is excited when light (electromagnetic radiation) interacts with the free (conduction) electrons of a metallic nanostructure which results in the collective excitations (oscillations) that lead to strong enhancements of the local electromagnetic fields surrounding the nanoparticles. Similar LSPR of $\mathrm{Cu}$ NPs with and without $\mathrm{Cu}_{2} \mathrm{O}$ layer controllably fabricated by nanosphere lithography was examined by Chan et al [42] with the help of UV-vis extinction spectroscopy and electrodynamics theory. The LSPR of the Cu NPs which is generally observed at $590 \mathrm{~nm}$ was found to significantly affect by the presence of copper oxides and the removal of the oxide species yields a dramatic difference in the observed LSPR. The formation of $\mathrm{Cu}_{2} \mathrm{O}$ layer on metallic $\mathrm{Cu}$ was reported to result into the red shift of the plasmonic peak from $590 \mathrm{~nm}$ to $890 \mathrm{~nm}$ that depends upon the oxide shell thickness [40]. Therefore, the observed peaks centered at ca. 737-740 nm in the present study can be attributed to the $\mathrm{Cu}_{2} \mathrm{O}$ layer formation on metallic $\mathrm{Cu}$.

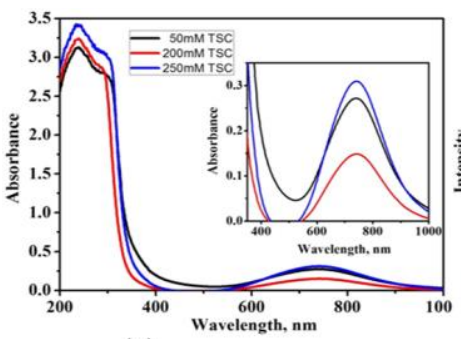

(a)

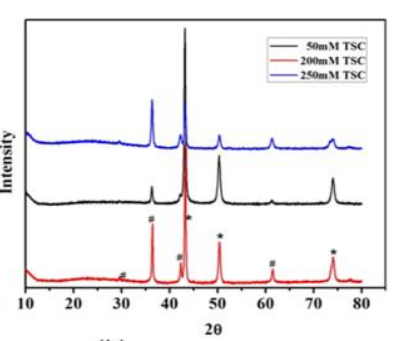

(b)
Fig. 1. (a) UV-vis absorption spectra of copper NS prepared with $50 \mathrm{mM}$ (black curve), $200 \mathrm{mM}$ (red curve) \& $250 \mathrm{mM}$ (blue curve) tri-sodium citrate at $3.2 \mathrm{~V}$ applied potential and $311 \mathrm{~K}$ temperature. The inset shows the plasmonic peak of $\mathrm{Cu} / \mathrm{Cu}_{2} \mathrm{O}$ NS.(b) Powder XRD pattern of copper nanostructures prepared with $50 \mathrm{mM}$ (black curve), $200 \mathrm{mM}$ (red curve), $250 \mathrm{mM}$ (blue curve) of tri-sodium citrate as an additive at $3.2 \mathrm{~V}$ and 311 $\mathrm{K}$. The peaks marked with ' $\star$ ' represents reflections from $\mathrm{Cu}^{\circ}$ and the peaks marked with \# corresponds to the reflections from $\mathrm{Cu}_{2} \mathrm{O}$ phases, respectively.

The XRD patterns obtained for the reddish-brown copper/copper oxide NPs synthesized with 50Mm, 200mM and $250 \mathrm{mM}$ are shown in Fig 1(b). The diffraction pattern 
shows peaks at $2 \theta$ values and corresponding (hkl) planes of $43.3^{\circ}(111), 50.5^{\circ}(200), 74.1^{\circ}$ (220) that matches with the $f c c$ metallic $\mathrm{Cu}$ (JCPDS, File No. 85-1326) and the other peaks in the same diffraction pattern at $2 \theta$ values of $29.58^{\circ}$ (110), 36.44 ${ }^{\circ}(111), 42.3^{\circ}(200), 61.4^{\circ}(220)$, and $73.9^{\circ}$ (311) that matches with the $\mathrm{Cu}_{2} \mathrm{O}$ (JCPDS, File No. 65-328), indicating that $\mathrm{Cu}_{2} \mathrm{O}$ also coexists together with metallic copper particles. The coexisting $\mathrm{Cu}_{2} \mathrm{O}$ is also considered to be due to some oxidation in air environment in addition to $\mathrm{Cu}$-hydroxide reduction process. No impurity diffraction peaks have been detected confirming the high purity of the product obtained by this method. Additionally, high reflection peak intensities for all the samples suggest that these are highly crystalline in nature.

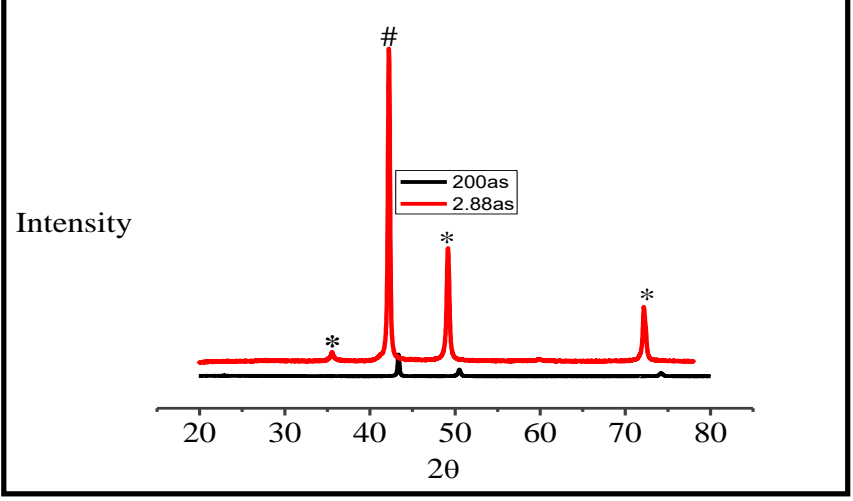

Fig. 2. Powder XRD pattern of copper nanostructures prepared with 200 $\mathrm{mM}$ (black curve) at $3.2 \mathrm{~V}$ and $311 \mathrm{~K}, 2.88 \mathrm{mM}$ (red curve) at $15 \mathrm{~V}$ and $373 \mathrm{~K}$ of ascorbic acid as an additive. The peaks marked with ' $\star \star$ ' represents reflections from $\mathrm{Cu}_{2} \mathrm{O}$ and the peaks marked with \# corresponds to the reflections from $\mathrm{CuO}$ phases, respectively.

The XRD pattern obtained from the reddish-brown powder has been shown in Fig. 2. The data was collected in the $2 \theta$ range of $10-80^{\circ}$ with a step size of $0.02^{\circ}$ and a step time of $1 s$. The diffraction pattern shows peaks at $2 \theta$ values and corresponding (hkl) planes of $43.27^{\circ}(111), 50.60^{\circ}$ (200), $74.1^{\circ}$ (220) that matches with the $f c c$ metallic $\mathrm{Cu}$ (JCPDS, File No. 85-1326) for the Cu Quantum Dot with $200 \mathrm{mM}$ ascorbic acid. The diffraction pattern shows peaks at $2 \theta$ values and corresponding (hkl) planes of $36.54^{\circ}$ (111) and $42.3^{\circ}$ (200) that matches with the $\mathrm{Cu}_{2} \mathrm{O}$ (JCPDS, File No. 65-328) for the leaf shaped $\mathrm{Cu}$ NPs with $2.88 \mathrm{mM}$ ascorbic acid and the other peaks in the same diffraction pattern at $2 \theta$ values of $35.47^{\circ}(002), 49.27^{\circ}(-202)$, and $72.23^{\circ}$ (311) that matches with the $\mathrm{CuO}$ (JCPDS, File No. 02-1041), indicating that $\mathrm{Cu}_{2} \mathrm{O}$ also coexists together with $\mathrm{CuO}$ particles.

The coexisting $\mathrm{Cu}_{2} \mathrm{O}$ is also considered to be due to some oxidation in air environment in addition to $\mathrm{Cu}$ hydroxide reduction process. No impurity diffraction peaks have been detected confirming the high purity of the product obtained by this method. Additionally, high reflection peak intensities for all the samples suggest that these are highly crystalline in nature. The morphology of the samples was investigated with the TEM measurements. All the TEM images shown in Fig. 3 clearly reveal the influence of concentration of TSC additive moieties on the size, shape and morphology of the electrochemically prepared plasmonic copper/copper oxide NS. When the TSC additive concentration is $50 \mathrm{mM}$, spherical copper/copper oxide NS with diameter ranging from $40-90.44 \mathrm{~nm}$ are also formed which is shown in Fig. 3(a). In this case, the nanoparticles with the elongated hexagonal shapes are also obtained which is shown in Fig. 3(b). The length of the hexagons obtained is found to be $92.4-121 \mathrm{~nm}$. In the same way both shapes particles are obtained with $200 \mathrm{mM}$ TSC as shown in Fig. 3 (c, d). But particles are in smaller size than the obtained particles with $50 \mathrm{mM}$ TSC. This observation is in good agreement with the previously indicated progressive nucleation mechanism where few spherical particles combine together to form the rectangular shape.

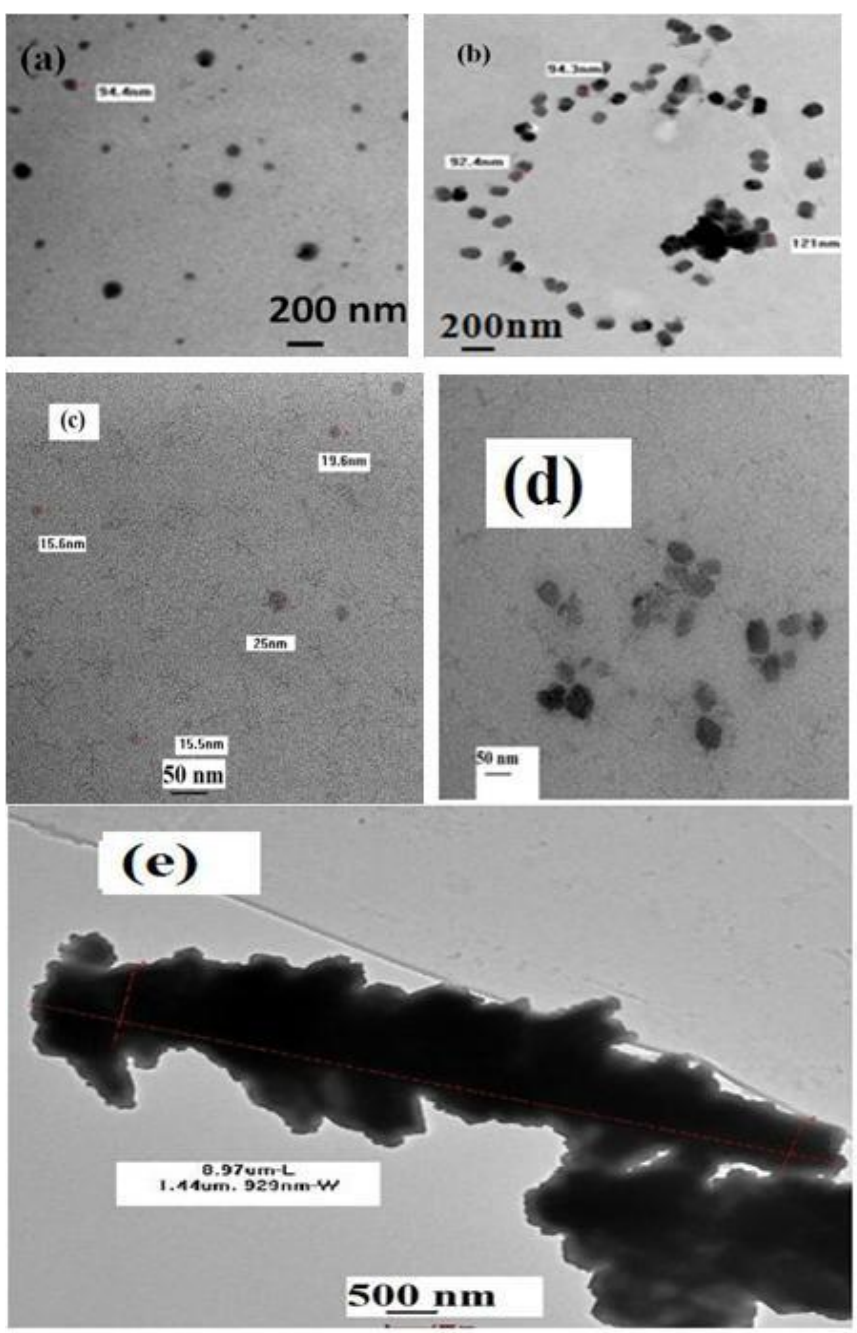

Fig. 3. (a, b) TEM images of plasmonic copper/copper oxide nanostructures prepared with $50 \mathrm{mM}$ (scale bar $200 \mathrm{~nm}$ ), (c, d) $200 \mathrm{mM}$ of tri-sodium citrate (scale bar $50 \mathrm{~nm}$ ) and (e) $250 \mathrm{mM}$ of tri-sodium citrate $(500 \mathrm{~nm}$ ) at an applied voltage of $3.2 \mathrm{~V}$ and temperature of $311 \mathrm{~K}$ (scale bar $50 \mathrm{~nm})$.

Fig. 3 (e) show the TEM images of copper/copper oxide NS obtained with $250 \mathrm{mM}$ of TSC additive concentration. In this case NS are obtained in leaf shapes ranging $8.97 \mathrm{um}$ length and 929nm width respectively. As we know that Energy Dispersive Spectroscopy (EDS) allows one to identify what those particular elements are presented and their relative proportions (Atomic \% for example). Herein EDS of leaf or dendrite shape $\mathrm{Cu}$ NPs has been shown in 
Fig. 4(c) which has been obtained from the corresponding generation of an X-ray spectrum from the entire scan area of the SEM (Fig. 4 (a)) and its results has been given in Table1. Herein, machine (Bruker Nano GmbH, Germany, Quantax) has been used for Fig. 4(a, c) and also has been shown in Fig. S2. The field emission scanning electron microscope (FE SEM) attached with Oxford-EDS system IE 250X max 80 with latest $80 \mathrm{~mm}^{2}$ model FEI Quanta 200 has also used to determine morphology as shown in Fig. S3 (see supporting information). These data predict that percentage ratio of metallic $\mathrm{Cu}$ is more than twice of $\mathrm{Cu}_{2} \mathrm{O}$ in this sample. The amount of $\mathrm{CuO}$ has been found very less as compared to $\mathrm{Cu}$ and $\mathrm{Cu}_{2} \mathrm{O}$. The composition of elements correlates with powder XRD data.

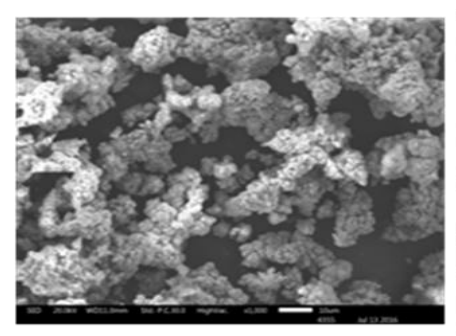

(a)

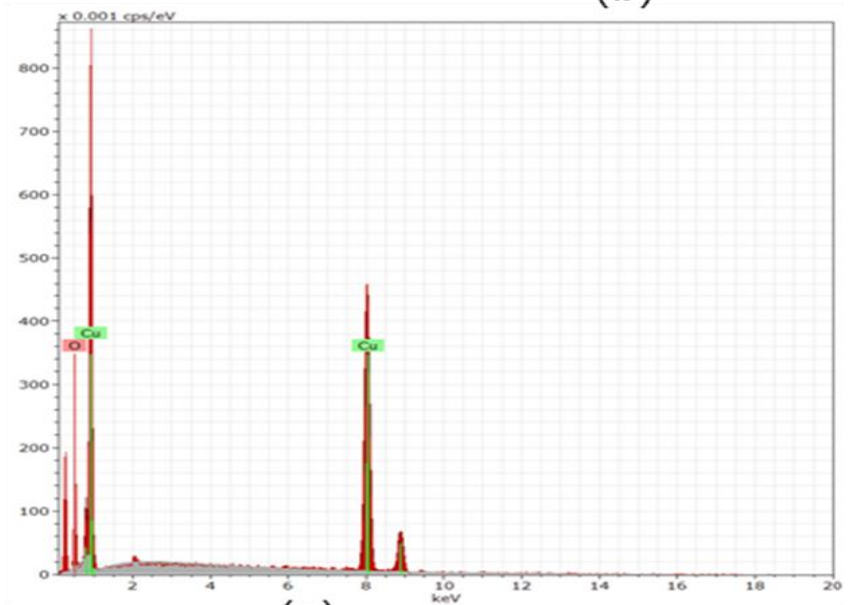

(c)

Fig. 4. (a) SEM images (b) TEM images (c) EDS data for Leaf or dentrite shaped $\mathrm{Cu}$ /copper oxides nanoparticles with $2.88 \mathrm{mM}$ ascorbic acid at $15 \mathrm{~V}$ and $373 \mathrm{~K}$.

Table 1. EDS data for Leaf or dentrite shaped $\mathrm{Cu}$ NPs with $2.88 \mathrm{mM}$ ascorbic acid.

\begin{tabular}{llccc}
\hline Element & series & [wt.\%] & [norm. wt.\%] & $\begin{array}{c}\text { [norm. } \\
\text { at.\%] }\end{array}$ \\
\hline Oxygen & K-series & 10.62159 & 9.382958 & 29.14124 \\
Copper & K-series & 102.5792 & 90.61704 & 70.85876 \\
& Sum: & 113.2008 & 100 & 100 \\
\hline
\end{tabular}

Fig. 4(b) shows the TEM images copper particles obtained with $2.88 \mathrm{mM}$ of ascorbic acid at applied potential of $15 \mathrm{~V}$ and temperature of $373 \mathrm{~K}$. More micrographs have been shown in Fig. S4 (see supporting information) which give us an exact idea of morphology and size of particles. It is clear from this Fig. 4 (a, b) that particles are formed in dendrite and leaf shaped.

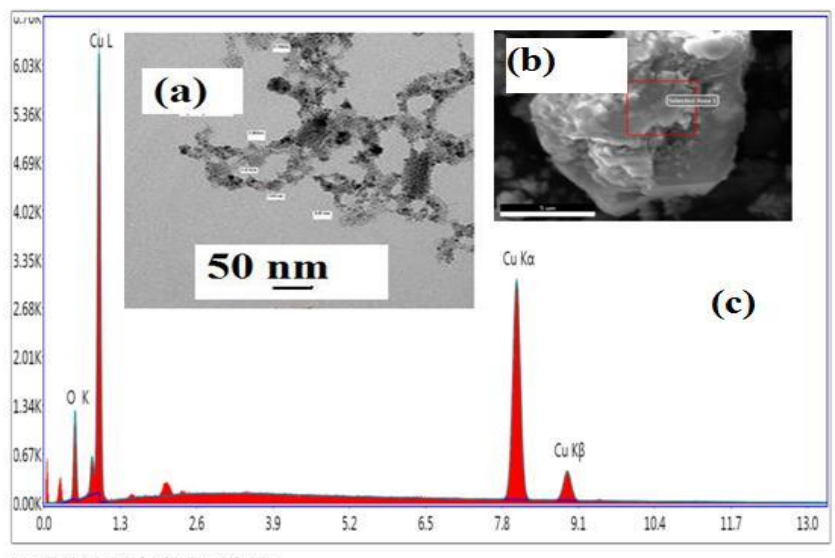

Isec 1000.00 Cints 0.000 keV Det Octane Plus Det

Fig. 5. (a) TEM images (b) SEM images (c) EDS data for quantum dot spherical shaped $\mathrm{Cu}$ /copper oxides nanoparticles with $200 \mathrm{mM}$ ascorbic acid.

Table 2. EDS data for $\mathrm{Cu}$ quantum dot prepared with $200 \mathrm{mM}$ at $3.2 \mathrm{~V}$ and $311 \mathrm{~K}$.

\begin{tabular}{lllll}
\hline Element & Weight & Atomic \% & Net Int. & Error \% \\
\hline O K & 7.73 & 24.96 & 64.82 & 8.8 \\
CuK & 92.2 & 75.04 & 478.58 & 2.15 \\
\hline
\end{tabular}

The SEM images and obtained EDS of spherical shaped Quantum Dot of $\mathrm{Cu}$ with $200 \mathrm{mM}$ ascorbic acid has been shown in Fig. (5b) and (5c) respectively. The machine (JEOL JSM 6610) has been used for getting these Figs. The results of EDS analysis have been given in Table 2. It is clear from the data table that the ratio for quantum dot of $\mathrm{Cu}$ has been found $75 \%$ and $\mathrm{Cu}_{2} \mathrm{O}$ of $25 \%$ respectively. Fig. 5(a) shows TEM images of copper nanoparticles synthesized at $3.2 \mathrm{~V}, 311 \mathrm{~K}$ with $200 \mathrm{mM}$ of ascorbic acid. These particles are very small in spherical shape ranging from 2.10 $\mathrm{nm}$ to $4.81 \mathrm{~nm}$. These particles are called quantum dot due to having very small diameters (mostly $2.1 \mathrm{~nm}$ ). These particles are smaller in size then previously reported by $\mathrm{Q}$. B. Zhang [29]. The population of particles are obtained in large amount. All the TEM images clearly reveal the influence of concentration of capping agent on the size, shape and number density of electrochemically synthesized copper nanoparticles.

Fig. 4(b) illustrates the TEM micrographs of copper nanoparticles directly grown with $2.88 \mathrm{mM}$ concentration of capping agent by the potentiostatic electroreduction at $15 \mathrm{~V}$ and $373 \mathrm{~K}$. In this case, the particles are formed in spherical as well as leaf-shape. The spherical particles have been obtained in range of $24.5-49.4 \mathrm{~nm}$. The smaller particles are formed in more amount ranging $24.5-29.5 \mathrm{~nm}$ then the particles having range of $40.5-49.4 \mathrm{~nm}$. The spherical particles are also deposited on the surface of leaf-shape particles. The SEM images have been obtained with two different machines do not indicate spherical morphology of particles. It means the exact morphology can be obtained 
with TEM images having very good resolution. The length of leaf has been obtained $646 \mathrm{~nm}$ and width towards bottom side of leaf $65.5 \mathrm{~nm}$ and towards top side of leaf $49.4 \mathrm{~nm}$ respectively. The width of leaf in mid place of leaf has been obtained $145 \mathrm{~nm}$. It means in this condition growth mechanism as well as nucleation process are altered. In this condition, leaf-shaped nanostructures have been obtained in larger amount.

We can say that as the temperature increases the rate of nucleation and growth increases and the bigger spherical particles are obtained and deposited on surface of leafshaped particles. Another reason is that as the concentration of capping agent decreases the capping capacity also decreases so that size of particles increases. So, we can say that concentration of capping agent as well as temperature of reaction are critical parameters which not only affects the size of particles but also shape of the particles. The results show a smooth decrease in the particle size accompanied by a corresponding increase in the particle number density. This is clear from all micrographs that $200 \mathrm{mM}$ concentration of ascorbic acid is a characteristic parameter at which we have obtained smallest size particles and these particles are designated as quantum dot. So the size of particles are best controlled in presence of $200 \mathrm{mM}$ of ascorbic acid at low temperature and low potential than in case of $2.88 \mathrm{mM}$ of ascorbic acid at high temperature and higher potential.

In this case the applied potential on the working electrode also acts as the main driving force for the dissolution of $\mathrm{Cu}^{+2}$ ions and deposition of copper nanoparticles, which plays an important role in tuning the nucleation and growth of copper nanoparticles.

\section{Set-2: Applied potential of $15 \mathrm{~V}$ at $373 \mathrm{~K}$}

As mentioned in experimental section, for Set-2 a DC voltage of $15 \mathrm{~V}$ was applied between copper anode and $\mathrm{Pt}$ cathode for the electro-dissolution of copper rod into $\mathrm{Cu}^{2+}$ ions at ca. $373 \mathrm{~K}$ temperature which then undergo series of reactions to produce copper/copper oxide NS. Here, we have observed that not only the crystallographic phases but also the shapes of copper/copper oxide NS can be controlled simply by changing the TSC concentration.

UV-visible absorption spectra of copper/copper oxide NS prepared at $15 \mathrm{~V}$ and $373 \mathrm{~K}$ in aqueous solution containing TSC additive with concentrations viz. $2.55 \mathrm{mM}$ (black curve) and $200 \mathrm{mM}$ (red curve) are shown in Fig. 6(a). Similar to the case noted in Set-1, two absorption peaks at 250 and $280 \mathrm{~nm}$ attributed to the oxidation product of TSC additive and a peak at $740 \mathrm{~nm}$ corresponding to the LSPR from copper oxide shelled metallic copper NS were also observed in Set-2, with $200 \mathrm{mM}$ of TSC additive concentration. However, for $2.5 \mathrm{mM}$ of TSC additive concentration, distinct behavior than that of $200 \mathrm{mM}$ TSC concentration has been noticed especially in case of LSPR absorption peak. An absorption peak at ca. $260 \mathrm{~nm}$ which is similar to that of Set-1 and $200 \mathrm{mM}$ TSC sample but with lower absorbance and slight shift in the absorption maxima has been observed for $2.5 \mathrm{mM}$ TSC concentration and can be attributed to the oxidation product of TSC additives.

Moreover, the LSPR peak observed at ca. $740 \mathrm{~nm}$ for 200 $\mathrm{mM}$ TSC concentration has now been observed to get broadened and blue shifted toward $460 \mathrm{~nm}$ for $2.5 \mathrm{mM}$ TSC concentration. This absorption maximum with much lower wavelength than the characteristic LSPR wavelength of metallic copper has been noticed and thus cannot be attributed to the LSPR absorption of metallic copper.

The powder XRD patterns of copper/copper oxide NS obtained with $2.55 \mathrm{mM}$ (black curve) and $200 \mathrm{mM}$ (red curve) concentration of TSC additive moieties at applied potential of $15 \mathrm{~V}$ and $373 \mathrm{~K}$ temperature are shown in Fig. 6(b). The major reflection peaks (marked with blue stars, ' $\star$ ') for XRD pattern of sample prepared with 2.55 $\mathrm{mM}$ TSC concentration which are observed at $2 \theta$ values of $35.3^{\circ}(110), 38.7^{\circ}(002), 48.5^{\circ}(-202), 53.5^{\circ}(020), 61.4^{\circ}$ (022) and $65.8^{\circ}(-222)$ matches with the $\mathrm{CuO}$ phase of copper oxide (JCPDS, PDF, File No. 41-0254), indicating that $\mathrm{CuO}$ has been the major product at this concentration of TSC. Additionally, few other peaks at $2 \theta$ values of $29.58^{\circ}$ (110), $36.44^{\circ}(111), 42.3^{\circ}$ (200), and $73.9^{\circ}$ (311) that matches with the $\mathrm{Cu}_{2} \mathrm{O}$ (JCPDS, File No. 65-328) are also noted, indicating that $\mathrm{Cu}_{2} \mathrm{O}$ phase coexists together with $\mathrm{CuO}$ phase. Interestingly, no reflection peaks corresponding to the metallic copper have been observed in this powder $\mathrm{XRD}$ pattern suggesting that the sample contains only $\mathrm{CuO}$ along with $\mathrm{Cu}_{2} \mathrm{O}$. The EDS Fig. 6(g) elemental analysis obtained from the selected area of SEM image (Fig. 6(c)) also correlates with powder XRD data.

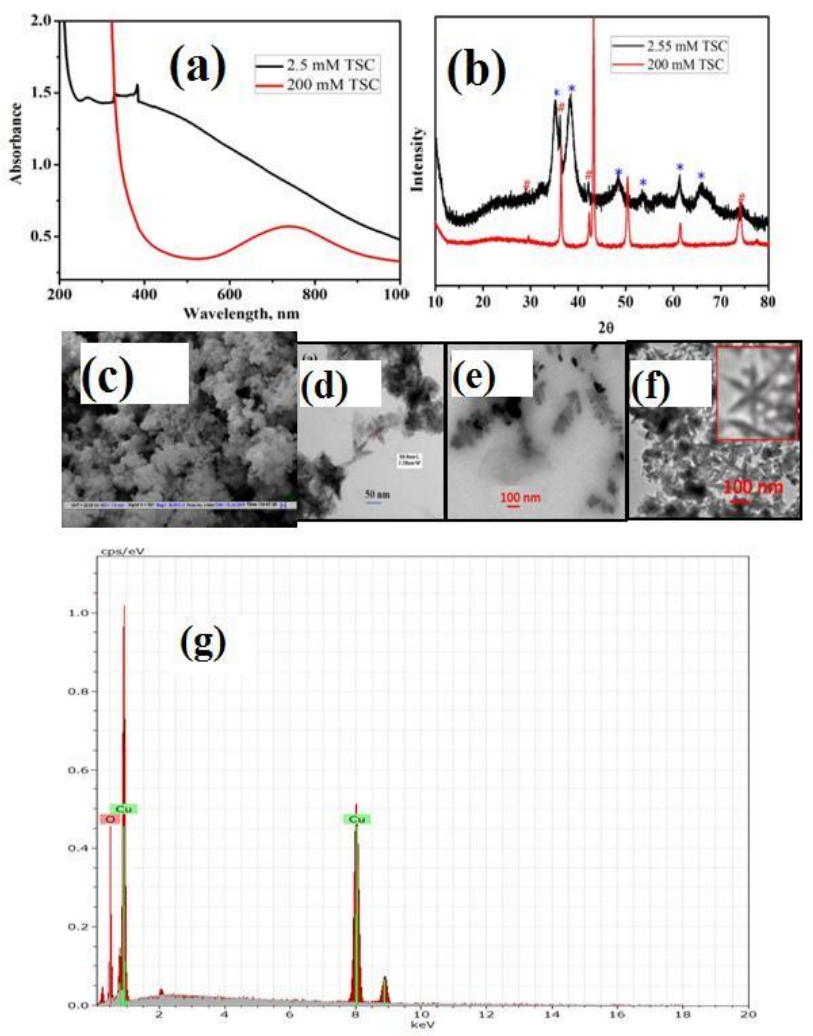

Fig. 6. (a) UV-visible absorption spectra, (b) Powder XRD pattern, the peaks marked with ' $\star$ ' (blue star) represents reflections from $\mathrm{CuO}$ and the peaks marked with '\#' (red hashtag) corresponds to the reflections from $\mathrm{Cu}_{2} \mathrm{O}$ phases, respectively. (c) SEM images (d, e, f) TEM images, with red border is an enlarged portion of the same image distinctly depicting the star shape. (g) EDS of copper/copper oxide NS prepared with $2.55 \mathrm{mM}, 200$ $\mathrm{mM}$ of tri-sodium citrate at $15 \mathrm{~V}$ And $373 \mathrm{~K}$. 
It is evident from the percentage elemental analysis of EDS of this sample that $\mathrm{Cu}_{2} \mathrm{O}$ and $\mathrm{CuO}$ are presented approximately in equal ratio. This percentage ratio also supports the copper/copper oxide NPs having the composition of $6 \mathrm{CuOCu}_{2} \mathrm{O}$. Which matches with the JCPDS File No.03-0879. Herein, machine (Bruker Nano GmbH, Germany, Quantax) has been used for Fig. 6(g). All the data have been given in Table 3.

Table 3. EDS data for star shaped copper/copper oxides NS prepared with $2.55 \mathrm{mM}$ of tri sodium citrate at $15 \mathrm{~V}$ and $373 \mathrm{~K}$.

\begin{tabular}{lrrll}
\hline Element & series & [wt.\%] & $\begin{array}{l}\text { [norm. } \\
\text { wt.\%] }\end{array}$ & $\begin{array}{l}\text { [norm. } \\
\text { at.\%] }\end{array}$ \\
\hline Oxygen & K-series & 13.00982 & 13.1281 & 37.5084 \\
Copper & K-series & 86.08924 & 86.8719 & 62.4916 \\
& Sum: & 99.09906 & 100 & 100 \\
\hline
\end{tabular}

In the light of these observations from XRD pattern, the absorption spectra recorded on sample obtained at $2.55 \mathrm{mM}$ of TSC concentration shown as black curve in (Fig. 6 (b)) has been re-interpreted. Firstly, the absence of LSPR absorption peak is expected due to the absence of metallic copper in the sample. Second, the band gap energy calculated from the absorption spectrum maximum of 460 $\mathrm{nm}$ which comes ca. $2.7 \mathrm{eV}$, can be attributed to that of nano-crystalline $\mathrm{Cu}_{2} \mathrm{O}$ phase and the broadening of the spectrum can be explained on the basis of the combination of absorption bands from $\mathrm{CuO}$ which has a variable band gap of $1.3-1.5 \mathrm{eV}$ and $\mathrm{Cu}_{2} \mathrm{O}$ which has a variable band gap of $2.1-2.5 \mathrm{eV}$ due to different oxygen and/or copper vacancies. However, in their nano-dimensions, both $\mathrm{CuO}$ and $\mathrm{Cu}_{2} \mathrm{O}$ are expected to have higher band gap energies than their bulk counterparts because of the size quantization effect. Therefore, the obtained broadness of the absorption spectrum from $2.7 \mathrm{eV}(450 \mathrm{~nm})$ to $1.7 \mathrm{eV}(720 \mathrm{~nm})$ is due to the mixed phases of $\mathrm{CuO}$ and $\mathrm{Cu}_{2} \mathrm{O}$ in the sample prepared with $2.55 \mathrm{mM}$ of TSC concentration.

\section{Effect of applied potential}

The shape of the particles obtained with concentration of TSC i.e. $2.55 \mathrm{mM}$ and $200 \mathrm{mM}$ has been shown in Fig. 6 (c, d, f) and Fig. 6(e) respectively. As we have discussed above that at $3.2 \mathrm{~V}$, mostly spherical and rectangle shaped $\mathrm{Cu} / \mathrm{Cu}_{2} \mathrm{O}$ NS have been obtained with $200 \mathrm{mM}$ of TSC. It means at two different applied voltages viz. $3.2 \mathrm{~V}$ and $15 \mathrm{~V}$, the morphology of NS has been observed different from each other. In this case at an applied potential of $15 \mathrm{~V}$, nanorods have been self-assembled into star and dendrite like structures. It appears that the rectangles obtained at $3.2 \mathrm{~V}$ become elongated and transform themselves into rod shape. Overall, it indicates that in addition to the concentration of TSC additive moieties, the applied voltage also plays an important role in the kinetics of nucleation and growth processes.

\section{Effect of reaction time}

We have found that the reaction time of electrolysis also alter the shape of the copper/copper oxide NS which is explained from Fig. 6 (d) and Fig. 6 (f). TEM images of copper/copper oxide NS prepared with $2.55 \mathrm{mM}$ of TSC and an applied voltage of $15 \mathrm{~V}$ but with two different reaction time intervals i.e. 30 and 60 minutes are shown in Fig. 6 (d) and Fig. 6 (f) respectively. As can be noticed from the images that the shape of copper/copper oxide NS was found to change from fluffy flowers at 30 minutes to star shape after an hour. The average dimensions of the petals; length of approx. $68 \mathrm{~nm}$ and width of ca. $7.3 \mathrm{~nm}$, respectively have been obtained. This again suggest that reaction time is also important parameter in order to control the shape of the copper/copper oxide NS using this electrochemical approach.

Thus, a simple electrochemical approach has been successfully employed for making plasmonic copper/copper oxide NS with variable shapes and morphologies. The advantages with this type of methodology is that several parameters such as applied voltage, electrolysis and electrodeposition time, and concentration of TSC additive moieties impart several degrees of freedom in controlling the size and shape of the NS.

\section{Kinetic study of photocatalytic degradation of methyl orange}

The degradation of methyl orange in the presence of $\mathrm{Cu}$ NPs has been studied spectrometrically by using Perkin-Elmer Lambda Bio $20 \mathrm{UV}$-vis spectrophotometer at a resolution of $1 \mathrm{~nm}$. Photocatalytic degradation of M.O has been studied using visible light of bulb of $100 \mathrm{~W}$ (source of light).

A comparative study has been performed to demonstrate the superior photocatalytic performance of the copper and copper oxide nanoparticles synthesized with two capping agent tri-sodium citrate and ascorbic acid. The maximum absorbance has been determined at $464 \mathrm{~nm}$ for pure methyl orange in basic medium. The degradation of methyl orange has been compared with copper nanoparticles synthesized at two different concentration of tri-sodium citrate $2.55 \mathrm{mM}, 250 \mathrm{mM}$ and $200 \mathrm{mM}$ ascorbic acid respectively. The experiments have been performed for one cycle for all three samples. The colour of the reaction mixtures faded, indicating that degradation has been occurred.

Measurements of the absorbance have been done at intervals of 5 min over a time span of 120 min shows a decrease in the absorbance maximum of methyl orange at $464 \mathrm{~nm}$. UV-visible spectra's of pure methyl orange and collected samples of degraded methyl orange with time in presence of $\mathrm{Cu}$ NPs with TSC and Quantum Dot of $\mathrm{Cu}$ with ascorbic acid in basic medium $(0.1 \mathrm{M} \mathrm{NaOH})$ have been shown in Fig. S5 (see in the supporting information).

However, the rate of maximum reduction in the absorbance of methyl orange has been obtained more prominent for the leaf shape nanoparticles with $250 \mathrm{mM}$ TSC then the copper and copper oxide star shape nanoparticles with $2.55 \mathrm{mM}$ TSC synthesized and spherical shape quantum dot of $\mathrm{Cu}$ with $200 \mathrm{mM}$ ascorbic acid (Fig. S5, black colour curve for pure methyl orange and 
other different colour curves for degraded methyl orange with different shaped copper/copper oxides nanoparticles, see in the supporting information).

The UV-visible spectra (no absorbance of collected sample at $35 \mathrm{~min}$ ) of degraded methyl orange with leaf shape particle capping via TSC $(250 \mathrm{mM})$ shows complete degradation of methyl orange in $35 \mathrm{~min}$. The mechanism of photocatalysis has been shown in Fig. 7(a). The kinetic study (plot $\ln \mathrm{C}_{\mathrm{t}} / \mathrm{C}_{0}$ vs time) for the degradation of M.O (15 $\mu \mathrm{M})$ in the presence of $\mathrm{Cu}$ NPs/ copper oxide NPs and quantum dot is shown in Fig. 7(b).

Considering the degradation as following first-order kinetics, the rate constants of both samples have been estimated from the graph $\ln \left(\mathrm{C}_{0} / \mathrm{C}_{\mathrm{t}}\right)$ versus time Fig. 7 (b).

(a)
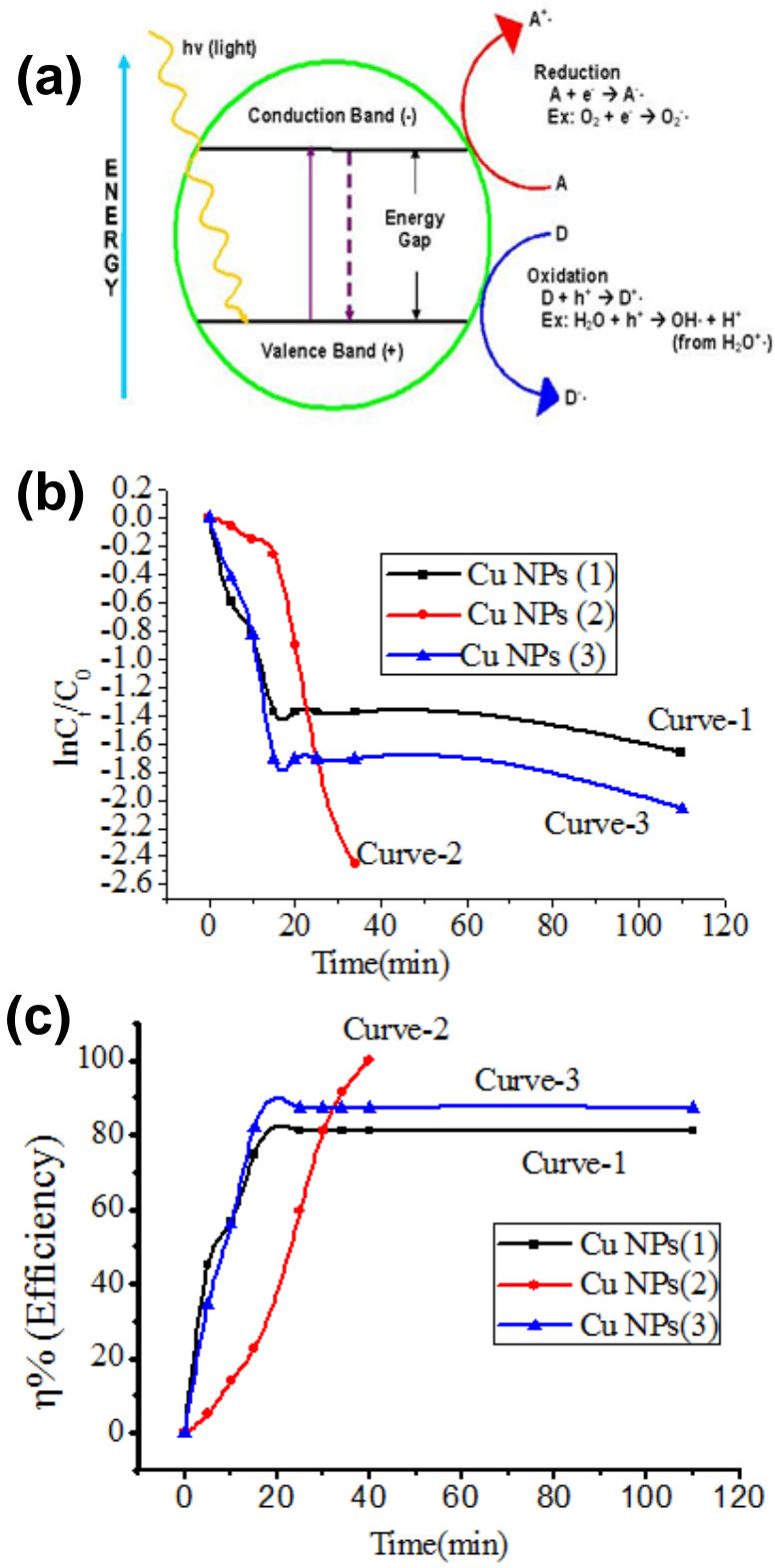

Fig. 7. (a) Mechanism of photocatalysis (b) $\ln C_{t} / C_{0}$ vs. time plots of the photocatalytic degradation of methyl orange (c) $\eta \%$ (efficiency) vs. time plots of the photocatalytic degradation of methyl orange in presence of $\mathrm{Cu}$ quantum dot with ascorbic acid $200 \mathrm{mM}$ (CuNPs (1)), black colour curve (1), leaf CuNPs with tri-sodium citrate $250 \mathrm{mM}$ (TSC) (CuNPs (2)), red colour curve (2), star shape CuNPs with tri-sodium citrate $2.55 \mathrm{mM}$ (TSC) blue colour curve (3).
The degradation efficiencies of the all three samples have been calculated according to the following equation:

$$
\eta(\%)=\left[\left(\mathrm{A}_{0}-\mathrm{A}_{\mathrm{t}}\right) / \mathrm{A}_{0}\right] \times 100=\left[\left(\mathrm{C}_{0}-\mathrm{C}_{\mathrm{t}}\right) / \mathrm{C}_{0}\right] \times 100
$$

where, $\eta$ represents the degradation efficiency, $\mathrm{C}_{0}$ the initial concentration of methyl orange, $\mathrm{C}_{t}$ the changed concentration of methyl orange at time $\mathrm{t}$ with prepared nanocatalyst ( $\mathrm{Cu}$ NPs), $\mathrm{A}_{0}$ the maximum absorbance of pure methyl orange or we can say without catalyst and $A_{t}$ the decrease in maximum absorbance of the methyl orange with time ( $\mathrm{t}$ min) in presence of nanocatalyst as consequence of the degradation of MO. Fig. 7 (b) shows the plot with linear relationship of natural logarithm of ratio of initial concentration of $\mathrm{MO}$ and relative remaining concentration after degradation versus the corresponding reaction time (s). Linear fit analysis has been used to evaluate the reaction rate constants of pseudo first order kinetics for the degradation of MO by different shaped copper nanostructures. The rate constant $k$ has been found to be $0.0102 \pm 0.00493,0.01389$ \pm 0.0066 and $0.076 \pm 0.01207 \mathrm{~min}^{-1}$ for the corresponding catalytic degradation of MO by star shaped CuNPs, spherical shaped $\mathrm{Cu}$ Quantum Dot and leaf shaped $\mathrm{Cu}$ NPs respectively. These results show that the rate constant in presence of CuNPs (250 mM TSC) has been found 7.0 times more than the star shape and quantum dot of $\mathrm{Cu}$ for degradation of MO.

Table 4. Comparative study of degradation of methyl orange with three different shaped copper/ copper oxides NPs when the reaction is monitored for $120 \mathrm{~min}$.

\begin{tabular}{lcc}
\hline Samples & $\begin{array}{c}\text { Efficiency } \\
(\%)\end{array}$ & $\begin{array}{c}\text { Rate constant } \\
\left(\mathbf{m i n}^{-1}\right)\end{array}$ \\
\hline $\begin{array}{l}\mathrm{Cu} \text { Quantum Dot } \\
\text { with ascorbic acid 200mM }\end{array}$ & $86 \%$ & 0.0139 \\
$\begin{array}{l}\text { Cu NPs star shape } \\
\text { With TSC 2.55 mM }\end{array}$ & $81 \%$ & 0.0102 \\
$\begin{array}{l}\text { Cu NPs Leaf shape } \\
\text { With TSC 250 mM }\end{array}$ & $100 \%$ & 0.0765 \\
\hline
\end{tabular}

The results have been summarized in Table 4 and statistical data has been given in Tables S1 and Table S2. The $\mathrm{Cu}$ NPs samples synthesized with $250 \mathrm{mM}$ TSC definitely has shown a better photocatalytic activity. The degradation of MO is almost comparable with other two samples. It is evident from the curve given Fig. 7(b) that rate of degradation of MO has been obtained very high than the reported value in the literature. In our results, the time taken for $100 \%$ degradation of MO is very less $(35 \mathrm{~min})$ with leaf shaped $\mathrm{Cu}$ NPs (250mM TSC) than the other star and spherical shaped $\mathrm{Cu}$ NPs. The time taken $60 \mathrm{~min}$ has been reported for degradation of methyl orange with $\mathrm{CuO}$ nanoparticles in the literature. These results suggest the efficiency of oxidative degradation of MO dye (81\%) in presence of (2.55 mM TSC, star shape) and (86\%) in presence of quantum dot for the same time $(120 \mathrm{~min})$ as shown in Fig. 7 (c). Differences in catalytic performance between TSC capped leaf shaped CuNPs and ascorbic acid 
capped spherical shaped $\mathrm{Cu}$ quantum dot can also be explained on the basis of the difference in the nanostructuresupport contact area that depends on the particles shape and size. It is known that many catalytic processes occur at the perimeter interface around the nanoparticles where the fraction of step sites increases significantly with decreasing particle size.

\section{Conclusion}

Thus, this study demonstrates shape dependent photocatalytic activity of CuNPs which have been synthesized by one step electrochemical method. The very high rate of degradation is evident that these NPs can be used over several cycles. The photocatalytic performance has been evaluated under bulb visible light illumination which shows that these $\mathrm{Cu}$ NPs can be very efficient sunlight-driven photocatalyst in degradation of different organic pollutants. From these result, it can be concluded that CuNPs prepared with $250 \mathrm{mM}$ TSC can act as best catalyst and play a very good role in the degradation of $\mathrm{MO}$ (100\%). Mechanism for the degradation of MO has been found same as summarized by S. S. Shinde, P. S. Shinde et al. in 2011. The synthesis has been carried out at an ambient temperature (at room temperature with $200 \mathrm{mM}$ TSC and $200 \mathrm{mM}$ ascorbic acid as a capping agent) without the use of any toxic chemicals, which makes this new technique attractive for the synthesis of $\mathrm{Cu}$ NPs and other nobel metal and metal oxide NPs with different shape. Thus, electrochemical synthesis is a novel technique which is simple and environment friendly. It is an easy, fast, and costeffective technique and doesn't involve any harmful and environmentally toxic chemicals used previously in conventional chemical reduction and other methods.

\section{Acknowledgements}

The authors wish to thank to Department of Chemistry, Department of Textile and Kusuma School of Biological Science, Indian Institute of Technology, Delhi, for providing facility for PXRD, SEM and TEM. The authors also wish to thank to Institute of Nano Science, Mohali and USIC, Delhi University, for providing facility for SEM and EDS. The authors wish to thank to Dr. Pravin P. Ingole, Assistant Professor, Department of Chemistry, Indian Institute of Technology Delhi for providing guidance during this research work.

\section{Supporting information}

Supporting informations are available from VBRI Press.

\section{References}

1. (a) Lee, J. H.; Shin, Y.; Lee, W.; Whang, K.; Kim, D.; Lee, J L.; Choi, P. W.; Kang, T.; Sci. Adv., 2016, 2, e1601838. (b) Jang, H.; Min, D. H.; ACS Nano, 2015, 9, 2696.

2. Lee, S.; Cha, E. J.; Park, K.; Lee, S. Y.; Hong, J. K.; Sun, I. C.; Kim, S. Y.; Choi, K.; Kwon, I. C.; Kim, K.; Ahn, C. H.; Angew. Chem., Int. Ed., 2008, 47, 2804.

3. Boisselier, E.; Astruc, D.; Chem. Soc. Rev., 2009, 38, 1759.

4. Debouttière, P.J.; Roux, S.; Vocanson, F.; Billotey, C.; Beuf, O.; Règuillon,F. A.; Lin, Y.; Rostaing, P. S.; Lamartine, R.; Perriat, P.; Tillement, O.; Adv. Funct. Mater., 2006, 16, 2330.
5. Anker, J. N.; Hall, W. P.; Lyandres, O.; Shah, N. C.; Zhao, J.; Van Duyne, R. P.; Nat. Mater., 2008, 7, 442.

6. Huang, X.; El-Sayed, I. H.; Qian, W.; El-Sayed, M. A.; J. Am. Chem. Soc., 2006, 128, 2115.

7. Hu, M.; Chen, J.; Li, Z. Y.; Au, L.; Hartland, G. V.; Li, X.; Marquez, M.; Xia, Y.; Chem. Soc. Rev., 2006, 35, 1084.

8. Jain, P. K.; Huang, X.; El-Sayed, I. H.; El-Sayed, M. A.; Plasmonics, 2007, 2, 107.

9. Lindquist, N. C.; Nagpal, P.; McPeak, K. M.; Norris, D. J.; Oh, S. H.; Rep. Prog. Phys., 2012, 75, 036501.

10. Schuller, J. A.; Barnard, E. S.; Cai, W.; Jun, Y. C.; White, J. S.; Brongersma, M. L.; Nat. Mater., 2010, 9, 193.

11. Atwater, H. A.; Polman, A.; Nat. Mater., 2010, 9, 205.

12. Giannini, V.; Fernández-Domínguez, A. I.; Heck, S. C.; Maier, S. A. Chem. Rev., 2011, 111, 3888.

13. Yang, M.; Zhao, X.; Ma, L.; Yao, Y.; Ding, Y.; Shen, X.; Electrochim. Acta, 2011, 56, 5783.

14. Park, K. S.; Seo, S. D.; Jin, Y. H.; Lee, S. H.; Shim, H. W.; Lee, D. H. ; Kim, D.W.; Dalton Trans., 2011, 40, 9498.

15. Kou, T.; Jin, C.; Zhang, C.; Sun, J.; Zhang, Z.; RSC Adv., 2012, 2, 12636.

16. Zhou, B.; Wang, H.; Yang, Z. Y.; Huang, X.; Lü, Z.; Sui, Y.; Su, W.; Mater. Chem. Phys., 2011, 126, 847.

17. Kou, T.; Wang, Y.; Zhang, C.; Sun, J.; Zhang, Z.; J. Chem. Eng., 2013, 223, 76.

18. Mishina, E. D.; Nagai, K.; Nakabayashi, S.; Nano Lett., 2001, 1, 401.

19. (a) Gao, X. P.; Yang, H. X.; Energy Environ. Sci., 2010, 3, 174. (b) Bian, Y.; Yeng, M.; Zhao, X.; Ma, L.; Jin, C.; Ding, Y.; Shen, X.; Adv. Mater. Res., 2012,509, 28.

20. Kaur, J.; Bansal, S.; Singhal, S.; Physica B , 2013, 416, 33.

21. Simamora, A.J.; Hsiung, T.L.; Chang, F.C.; Yang,T. C.; Liao, C. Y.; Wang, H. P.; Hydrogen Energy, 2012, 37, 13855.

22. Song, X. ; Sun, S.; Zhang, W. ; H. Yu, Fan, W. J. Phys. Chem. B, 2004, 108, 5200 .

23. D. Li, Y. H.; Leung, A. B. ; Djurisic, Z. T.; Liu, M. H.; Gao, X. J.; Chan, W. K.; J. Cryst. Growth, 2005, 282, 105.

24. Gao, X. P.; Bao, J. L.; Pan, G. L.; Zhu, H. Y.; Huang, P. X.; Wu, F.; Song, D. Y.; J. Phys. Chem. B, 2004, 108, 5547.

25. Maksimovic, V.; Pavlovic, L. Pavlovic, M.; Tomic, M.; J. Appl. Electrochem., 2009, 39, 2545.

26. Pavlovic, M.; Pavlovic, L.; Maksimovic, V.; Nikolic, N.; Popov, K.; Int. J. Electrochem. Sci., 2010, 5, 1862.

27. Nikam, A. V.; Arulkashmir, A.; Krishnamoorthy, K.; Kulkarni, A. A.; Prasad, B. L. V.; Cryst. Growth Des., 2014, 14, 4329.

28. Nekouie, R. K.; Rashchi, F.; Joda, N. N. ; Powder Technol., 2013, 237,554 .

29. Zhang, Q. B.; Hua, Y. X.; Phys. Chem. Chem. Phys., 2014, 16, 27088.

30. Popov, K. I.; Pavlovic', M. G.; Maksimovic, M. D.; J. Appl. Electrochem., 1982, 12, 525.

31. Xu, Q.; Wu, Z.; Wang, S.; Yi, J.; Hydrometallurgy, 2006, 82, 154.

32. Tesakova, V.; Parfenyuk, M.; Surf. Eng. Appl. Electrochem., 2010, 46,11

33. Jafar, S.; J Eng. Technol., 2009, 27, 2308.

34. Tantavichet, S.; Damronglerd, O.; Chailapakul, N. Electro Chimica Acta, 2009, 55, 240.

35. Ingole, P. P. Bhat, M. A.; Mater. Res. Express, 2016, 3(3), 035001.

36. Ingole, P. P.; Abhyankar, R. M.; Prasad, B. L.V.; Haram, S. K.; Mater. Sci. and Eng., B, 2010, 168, 60.

37. Ji, X.; Song, X.; Li, J.; Bai, Y.; Yang, W.; Peng, X. ; J. Am. Chem. Soc., 2007, 129, 13939.

38. Pillai, Z. S.; Kamat, P. V.; J. Phys. Chem. B, 2004, 108, 945-951.

39. Henglein, A.; Giersig, M.; J. Phys. Chem. B, 2000, 104, 6767.

40. Pong, B. K.; Elim, H. I.; Chong, J. X.; Ji, W.; Trout, B. L.; Lee, J. Y.; J. Phys. Chem. C, 2007, 111, 6281.

41. Xiong, J.; Wang, Y.; Xue, Q.; Wu, X. Green Chem., 2011, 13, 900.

42. Zhao, G. H.; Hicks, J. E.; Schatz, M. G. C.; Van Duyne, R. P.; Nano Lett., 2007, 7(7), 1947.

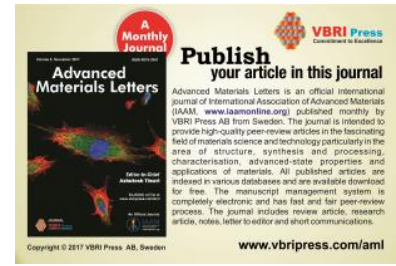




\section{Supporting Information}

Include all the supporting information data here like

a) Experimental setups/ Schematics (Fig. S1)

b) Figures( Fig. S2, Fig. S3, Fig. S4, Fig. S5)

c) Tables ( Table S1 and Table S2)

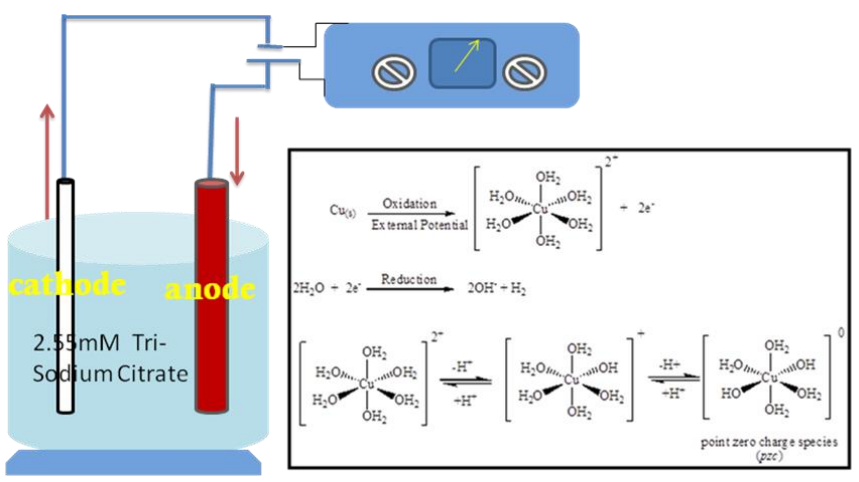

Fig. S1. Schematic electrochemical synthesis of copper nanoparticles with tri-sodium citrate (TSC).

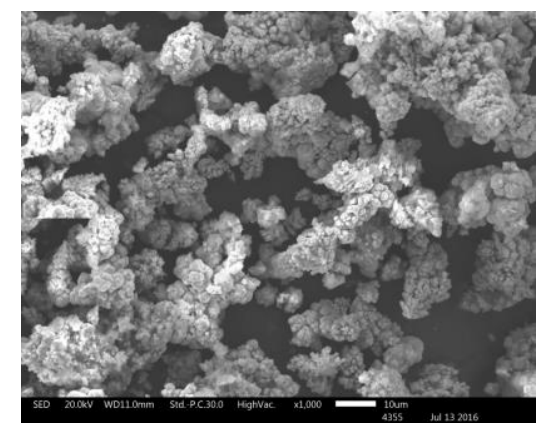

Fig. S2. SEM images of leaf or dendrite shaped $\mathrm{Cu}$ and copper oxides nanoparticles synthesized with $2.88 \mathrm{mM}$ ascorbic acid at applied potential of $15 \mathrm{~V}$ and temperature of $373 \mathrm{~K}$

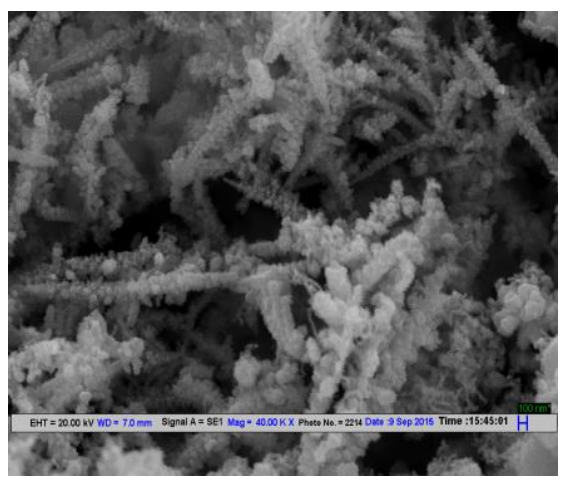

Fig. S3. SEM images of leaf or dendrite shaped $\mathrm{Cu}$ and copper oxides nanoparticles synthesized with $2.88 \mathrm{mM}$ ascorbic acid at applied potential of $15 \mathrm{~V}$ and temperature of $373 \mathrm{~K}$. 


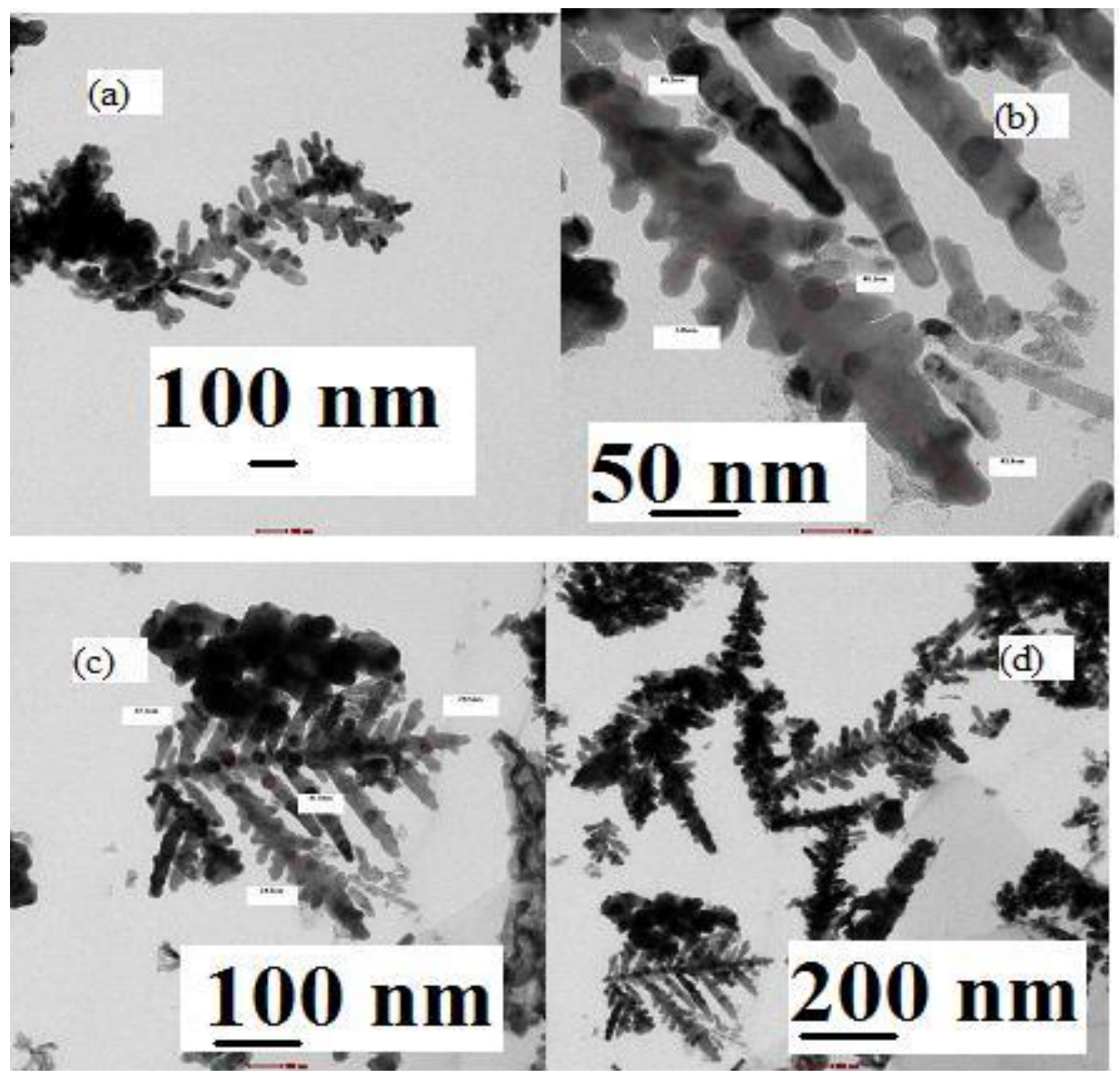

Fig. S4. TEM images of leaf or dentrite shaped Cu NPs synthesized with $2.88 \mathrm{mM}$ ascorbic acid at applied potential of $15 \mathrm{~V}$ and temperature of $373 \mathrm{~K}$.

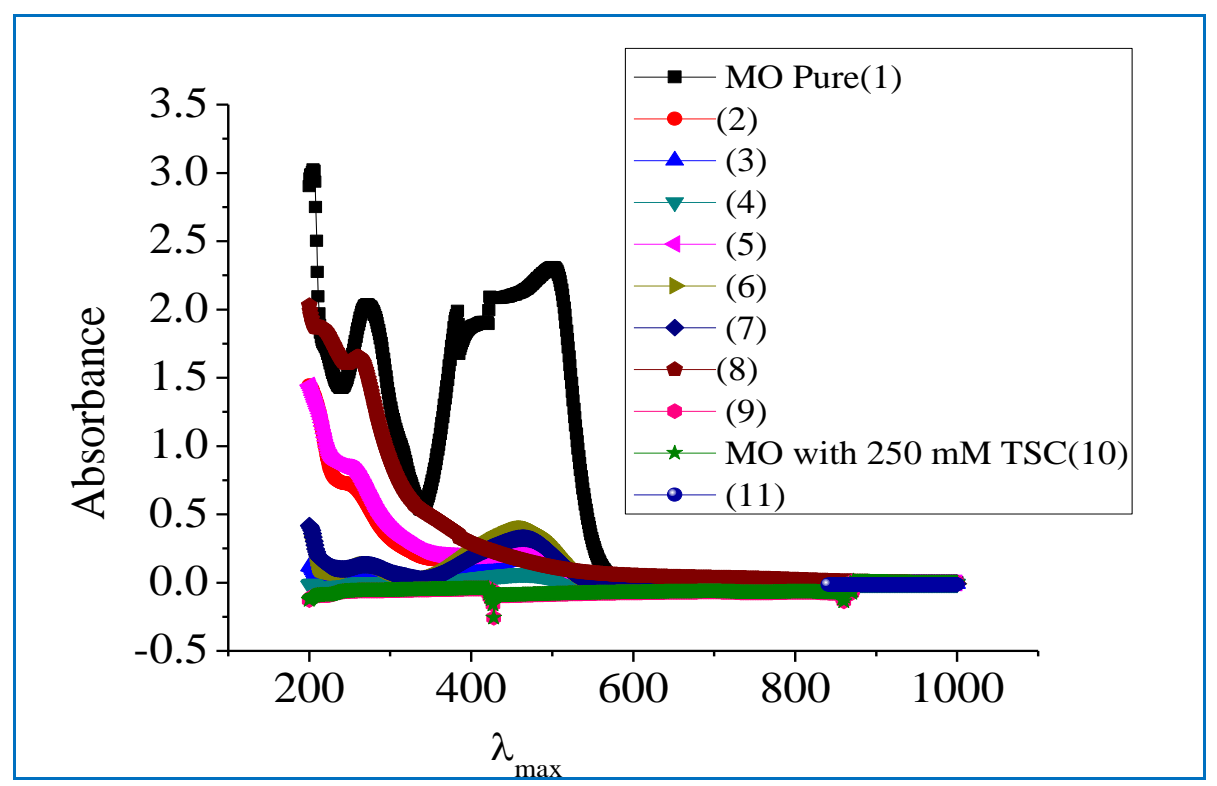

Fig. S5. Comparative UV-visible spectra of methyl orange pure and degraded methyl orange in presence of quantum dot of $\mathrm{Cu}$ with $200 \mathrm{mM}$ ascorbic, spherical shaped CuNPs with $200 \mathrm{mM}$ TSC and star shaped Cu NPs with $2.55 \mathrm{mM}$ TSC. 
Table S1. Linear fit data for degradation of methyl orange with different Cu NPs, pseudo first order kinetics.

\begin{tabular}{cccc} 
S. No. & Standard error & Rate constant/min & Sample (Cu NPs) \\
1 & 0.00493 & 0.0102 & $2.55 \mathrm{mM} \mathrm{TSC}$ \\
2 & 0.0066 & 0.0139 & $200 \mathrm{mM} \mathrm{Ascorbic}$ \\
3 & 0.01207 & 0.0765 & $250 \mathrm{mM} \mathrm{TSC}$ \\
\hline
\end{tabular}

Table S2. Statistics of linear fit data for degradation of methyl orange with different CuNPs, pseudo first order kinetics.

\begin{tabular}{lccc} 
No. of Points & 8 & 8 & 7 \\
Degree of freedom & 6 & 6 & 5 \\
Residual of Sum of square & 2.5605 & 1.2568 & 0.6069 \\
Adj R-Square & 0.3289 & 0.3198 & 0.8671 \\
\hline
\end{tabular}

